Document downloaded from:

http://hdl.handle.net/10251/83176

This paper must be cited as:

Belda Miquel, S.; Boni Aristizábal, A.; Cuesta Fernandez, I.; Peris Peris, J. (2016). Are rights-based approaches helping (re) politicise development NGOs? Exploring the Spanish case. International Development Planning Review. 38(2):135-157. doi:10.3828/idpr.2016.7.

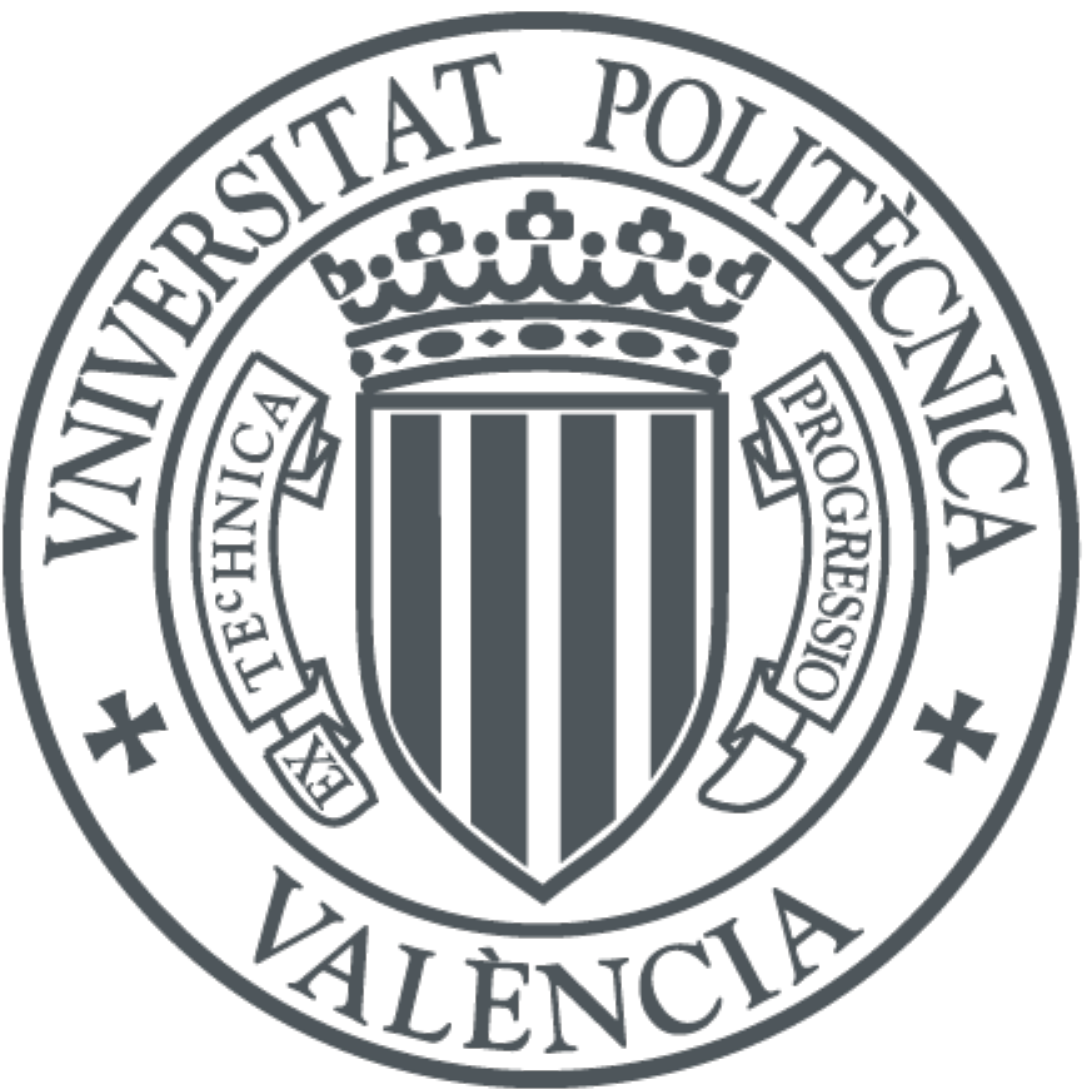

The final publication is available at

http://doi.org/10.3828/idpr.2016.7

Copyright Liverpool University Press

Additional Information 


\title{
Are Rights-Based Approaches helping (re)politicise development NGOs? Exploring the Spanish case
}

\author{
Belda-Miquel, Sergio ${ }^{1}$; Boni, Alejandra ${ }^{1}$; Cuesta Fernández, Iván ${ }^{2}$; Peris, Jordi ${ }^{2}$ \\ ${ }^{1}$.INGENIO (CSIC-Universitat Politècnica de València) \\ ${ }^{2}$ Group of Studies on Development, Cooperation and Ethics, Universitat Politècnica de València
}

This paper has been published in the International Journal of Development Planning Review: Belda-Miquel, S., Boni, A., Cuesta-Fernández, I., \& Peris, J. (2016). Are rights-based approaches helping (re) politicise development NGOs? Exploring the Spanish case. International Development Planning Review, 38(2), 135-157.

\section{Acknowledgments}

This study forms part of the research project La movilización social como dimensión estratégica de la educación para el desarrollo: Estudio de experiencias desde una perspectiva $\mathrm{N} / \mathrm{S}$ en el marco de la ciudadanía global y del enfoque basado en derechos, funded in 2011 by the Spanish Agency of International Cooperation (AECID) in its call for research projects in development studies (11-CAP20995). 


\begin{abstract}
Over the last decades, the rise of managerialism had contributed to the depoliticisation of practices and discourses of Non-Governmental Development Organisations (NGDOs). From some quarters, the adoption of rights-based approaches (RBAs) has been seen as an opportunity to challenge this process. From this standpoint, the article aims to explore to what extent RBAs may have helped (re)politicising the discourses of NGDOs. In order to do so, we look at look at how 11 Spanish NGDOs that have adopted a RBA are reshaping their understandings of issues related with power, participation and accountability. The analysis reveals that the adoption of RBAs seems to be a process full of diversity, tensions and contradictions, both across and inside organizations. If in some cases RBAs may have consolidated managerialism, the opposite is also true. We hypothesise that external requirements from donors, as well as the different backgrounds, profiles, organisational cultures and previous political stances of the organisations may be shaping how they conceive RBAs and, consequently, how they adopt them.
\end{abstract}

Keywords: Rights-based approaches, development NGOs, managerialism, politics, power, participation, accountability. 


\section{Introduction: The de-politicisation of development and the chance of rights- based approaches}

In the last two decades, the 'depoliticisation' of development has come under fierce criticism (Ferguson, 1994). Skeptics argue that hegemonic frames consider development problems as technical and managerial ones (Wallace et al., 2007;Mowles et al., 2008). For dominant perspectives, experts play a key role as the sole actors capable to tackle the social problems addressed by development organizations (Srinivas, 2009). Following Li (2007), de-policitisation proceeds as programmers enact two key routines: 'problematisation', that is, the identification of deficiencies that need redress; and 'rendering technical', or the representation of domains as intelligible fields with specifiable limits and particular characteristics, manageable by experts in development interventions. In so doing, technical questions are simultaneously rendered as non-political. Experts usually exclude political-economic issues from their analyses and prescriptions, and focus instead on the capacities amongst the poor rather than on the practices through which one social group impoverishes another (Li, 2007). By posing deeply political questions in technical terms, the status quo and the system are not challenged (Ferguson, 1994).

Following this trend, a growing number of Non-Governmental Development Organizations (NGDOs) would have assumed this practice of framing the problems they deal with as purely technical ones (Srinivas, 2009). They have de-politicised their diagnosis and prescriptions as part and parcel of a broader trend towards the acceptance of managerialism. It is not only that, along the process, development issues are-framed as technical; also, the market inspires a comprehensive de-politicised rationale underpinned by concepts coming from the private sector, such as supplier, client and product (Quarles van Ufford \& Giri 2003), as well as by notions such as effectiveness, efficiency, resources, and strategy (Maier \& Meyer, 2011). This process would have contributed to set aside the political and activist profile that many NGDOs may have had in the past (Choudry \& Shragge, 2011; Fowler, 1998).

This process of framing political questions in technical terms is strictly political. Some authors consider that this process is part of an ideological agenda which serves to the interests of dominant classes or particular powerful actors (Meyer, Buber, \& Aghamanoukjan, 2012; Parker, 2002), while others do not consider that there are always hidden interests of motivation to be unveiled (Li, 2007, 1999). In any case, 
there is some agreement in the fact that these processes are problematic for local stakeholders, institutions and cultures (Dar \& Cooke, 2008). Even if there is always space for resistance (Mosse, 2005), local actors are considered by northern organizations as objects of development and as vehicles of the projects (Dar \& Cooke, 2008).

In this context, discourses which had been prevalent for decades amongst human rights organisations entered in the late nineties the aid sector, reorienting the framings of some NGDOs accordingly (Uvin, 2007). These new discourses have been articulated around the so-called 'right-based approaches' (RBAs). Some have regarded RBAs as an opportunity to re-politicise both the notion and the practice of development (Gready, 2009; Nyamu-Musembi and Cornwall, 2004). Others, however, feared that the colonisation of development by rights discourses might imply the juridification of politics and favour a strictly legalistic approach to development problems and NGDOs (Evans, 2005; Blichner and Molander, 2008), which may consolidate managerialist perspectives.

A growing literature citing case studies of adoption of RBAs testifies to the relevance of the topic (see, for example, Aberese, Akua and Crawford, 2013; Schmitz, 2012; Kindornay et al. 2012; Cornwall and Molineux, 2006; Gready and Ensor, 2005; NyamuMusembi and Cornwall, 2004; Offenheiser and Holcombe, 2003). Yet even amongst those studies it is rare to find analyses addressing the contribution of RBAs to the (re)politicisation of international development organisations. Our study aims to contribute filling that gap. Thus, we set out to ask ourselves whether the adoption of RBAs by some Spanish NGDOs may have contributed to (re)politicise their discourses on what they do and how. From the discussion on the different general perspectives on rights, and drawing on the notions of power, participation and accountability, we identify key issues and build a framework from which to explore the discourses of a sample of 11 Spanish NGDOs which have adopted a RBA.

The Spanish case is relevant and representative for the aims of our study, as in the Spanish context we can identify the key processes already noted: a diversity of NGDOs rapidly professionalizing whilst, at the same time, de-politicising themselves (Fernández et al., 2014; Martínez-Oses, 2011; Revilla, 2002); a non-negligible number of charities enthusiastically adopting RBAs, regardless of their organizational profile; 
and a substrate of scholars and professionals supporting the adoption of RBAs as a way out to re-politicise NGDOs (Fernández, 2013).

The rest of the paper proceeds as follows: In the next section we characterize the common ideas and the different perspectives on RBAs, and propose an original differentiation drawing on the difference between legalist and constructivist perspectives on rights. Later on, we draw on the concepts of participation, power and accountability to build a framework from which to identify and asses key issues in the case studies in order to explore the impact of the adoption of RBAs in the (re)politicization of the NGDOs under study. After that, we describe our methodology. That is followed by the discussion of results. We conclude by offering some tentative insights about the landscape of the adoption of RBAs across Spanish NGDOs, and offer some avenues for further research.

\section{RBAs as a diversity of perspectives}

A common feature of RBA discourses is the redefinition of the nature of development problems. They recast development in a new mould in which passive 'beneficiaries' turn into rights-holders (Schmitz, 2012). Towards them, states and other actors bear a responsibility in ensuring that their rights are guaranteed (Nyamu-Musembi and Cornwall, 2004). Some other basic principles that RBAs share can be identified (Kindornay et al., 2012): poverty is framed in the language of rights -and no longer as a set of 'needs' that 'clients' have; development interventions should challenge the root causes of poverty and rights denial (Schmitz, 2012); the focus should be on development processes and not exclusively on outcomes (Aberese at al., 2013); development is considered as an entitlement, rather than as benevolence or charity (Gready, 2009).

It has been also said that RBAs have in particular contributed to reframe concepts not entirely new to the development discourse, such as power, participation and accountability (Gready, 2009). Firstly, RBAs claim to compel NGDOs to understand their interventions as a challenge to the existing power relations that underpin underdevelopment. Siding the powerless against the powerful who deny their rights comes as a natural consequence (ActionAid, 2010). Secondly, RBAs have advocated for a more transformative participation (Hickey and Mohan, 2005). From this perspective, 
participation as a mere assessment of needs or to improve efficiency in projects should be superseded in order to promote participation for advocacy and mobilisation that can democratise public debates and policy making (McGee, 2010). Finally, it has been said that RBAs can also make a significant contribution for reframing accountability in the development discourse. By adopting RBA, NGDOs should back efforts to hold the state accountable whilst at the same time making non-state actors accountable as well, resecuring responsibilities and remedying capacity gaps (Gready, 2009).

Yet, at the same time, RBAs are diverse and constitute an arena for contestation - also within NGDOs (Uvin, 2007) - and conform a sort of Tower of Babel from which a chorus of voices and agendas are broadcast (Cornwall and Molineux, 2006; Gready, 2008). Given that diversity, scholars have proposed typologies for differentiating RBAs. For instance, RBAs have been classified according to who is targeted in order to enforce rights, namely the state, civil society or local communities (Aberese, 2013). RBAs have also been differentiated by paying attention to the strategies they endorse (Plipat, 2005): populist - e.g. popular organisation or networking; campaign-driven e.g. advocacy or lobbying; legalist - e.g. court cases, law reform or filing claims; or community-focused - e.g. rights awareness raising at community level. Another distinction discriminates between RBAs by looking at the norms in their inception. Accordingly, RBAs can be inspired by international and regional treaties, constitutional rights, the policies and principles of donors and executive agencies, or normative beliefs (Guari and Gloppen, 2012). Yet for all their diversity, RBAs have not been able to clear away the suspicion that they merely bring about rhetorical adjustments to mainstream development discourses (Kirdonay et al., 2012; Hickey et al., 2009), hardly challenging managerial and de-politicised discourses.

In order to build a relevant distinction among RBAs form the point of view of their potential contribution to the (re) politicisation of development discourse, we propose an original typology departing from the differentiation proposed by Nyamu-Musembi and Cornwall (2004). According to them, RBAs differ on the different sources of legitimacy which are recognized for the rights advocated. Accordingly, some RBAs rely on rights codified into law, whereas others also consider the rights emerging from the struggles of exploited groups - whether accorded legal status or not. For the latter, rights can be rearticulated 'on a notion forged in human struggle and action that goes beyond the confines of "what the law says" to acknowledge the need for broader societal changes' (VeneKlassen et al., 2004, p. 8). Codified and un-codified rights thus 
emerge as the tip of the iceberg of two camps championing legalistic and constructivist perspectives, respectively. It goes without saying that the former is far more hostile to politics than the latter. The insights of Nyamu-Musembi and Cornwall are not merely theoretical; their distinction may also shape the strategies advocated towards both duty-bearers and rights-holders. We suggest that legalistic RBAs tend to advocate for strategies towards duty-bearers such as enforcing laws, building capacities, or lobbying policymakers; coherently, the suitable strategies towards rights-holders range from raising awareness to strengthening social actors in their capacities for advocacy to building coalitions towards the accomplishment of codified rights. Constructivist RBAs, on the other hand, assume that the law can be supported, ignored or contested by means of a direct, indirect or purely strategic use (Gready, 2009). Accordingly, tools such as advocacy, awareness raising and networking also become merely tactical. On the contrary, it is paramount to support bottom-up processes of mobilisation, activism, creativity, and in general any struggle and perspective seeking broader changes in society.

Understood as such, constructivism perspectives may avert the juridification of rights as well as of politics when using the language of rights. Yet, to be an effective safeguard, these perspectives have to derive their strength from the relations nurtured throughout the process in which rights are articulated and accepted. In development, specifically, the relations between NGDOs and social organizations - as long as they are genuine political actors in the construction of bottom-up demands - are chief (Choudray and Shragge, 2011; Fernández et al., 2013). Hence, partnerships in aid unfold as 'patterns of social relations shaped by context-specific and historically derived configurations within the broader fields of power and meaning in global and local politics' (Eyben, 2008, p. 20). Vigorous partnerships witness social actors not only shaping their relations, but also being shaped by them (Eyben, 2008). The relational dimension intrinsic to constructivist RBAs may thus help pre-empting the reification of law brought about by the juridification of rights, and the drift from political into legalistic arenas.

Those organizations viewing RBAs with a constructivist mindset might be more prone to gain insights deriving from political economy and, more precisely, from the connection of the latter with the diagnoses and strategies championed by a RBA. Political economy allows articulating rights around issues of control, production and distribution of resources ( $\mathrm{Li}, 2007)$ also reframing development as a contextual, 
conflictive and political process (McCourt, 2008), and embracing an agenda of social transformation (Choudry and Shragge, 2011; Gulrajani, 2010). From a legalist perspective of rights and RBAs, instead, experts are more easily considered as the sole agents legitimised to tackle developmental challenges (Srinivas, 2009), which can be framed ignoring political-economic issues in their diagnoses and prescriptions, representing domains in purely technical and non-political terms (Li, 2007), following the juridic jargon.

\section{Analysing RBAs: power, participation and accountability from a radical perspective}

We now connect the ideas exposed with three core concepts in the development sector which, as it was mentioned, are also core questions which RBAs affirm to have reframed: power, participation and accountability. From these concepts and the discussion of criticisms to RBAs we identify key issues in which to focus in the analysis of the case studies, and we propose a perspective from which we can address these issues in order to explore the contribution of the adoption of RBAs for the (re)politicisation of organizations. This perspective is called 'radical', as long as it is tries to recall the political implications of the concepts mentioned. We assume that these notions have become buzzwords used in the mainstream development discourse (Cornwall, 2007). However, we consider that it is possible to reclaim the radical origins and the potentially radical implications of these notions for analysing and rethinking development discourse and practice. Following authors as McCourt (2008) and Mowles (2010), we consider that critical engagement with some already dominant theories and concepts in the development jargon is possible and desirable in order to recover their transformatory potential.

Addressing the issue of power in a first place, it is to say that, even though the most enthusiastic proponents of RBAs claim that the latter transfer the challenge of unequal power relations to the centre of their analyses and actions, we argue instead that rights-based perspectives may be superficial and diffuse in how they deal with power (Gready, 2009). Accordingly, NGDOs, though resorting to discourses about rights, may be reproducing certain forms of hidden power in their relationships with their local partners (Gaventa, 2006a). Hidden power - also referred to as the 'mobilization of bias' (Schattschenider, 1960, p. 71) - creates barriers for participation by imposing 
certain issues and framings, a particular agenda as well as advantageous rules of the game. When it comes to NGDOs, RBAs might be forcing upon their partners 'universal' or 'aseptic' discourses on rights, on the causes of rights violations, and on the strategies to challenge them. As frequently reminded, such discourses are rooted in the western hegemonic liberal logic that underpins mainstream development discourses (Escobar, 2008). As a consequence, some NGDOs would be indeed constraining contestation and mobilization within the boundaries of a certain framework (Gauri \& Gloppen, 2012). Specifically, some rights discourses might be imposing a framework which excludes political issues and the structure of political economy relations $(\mathrm{Li}, 2007)$ when addressing the causes of rights violations, or the strategies for building rights.

Conversely, NGDOs embracing a more 'radical' stance should be sensible to the process of production of frames and discourses on rights, and would be opened to local knowledge and visions on rights, causes of rights violations and strategies for social change which emerge from people's everyday struggles (Choudry \& Shragge, 2011). Such NGDOs would embrace notions of rights rooted in particular contexts, be they recognized by law or derived from liberal frames or not. By doing so, they would expand their abilities to challenge neo-liberalism and current hegemonic development models (Belda et al., 2012; Eyben, 2005). Lastly, a radical stance would push NGDOs beyond merely 'supporting' and 'promoting' social mobilisation, advocacy or coalition building, to engage politically instead and take sides in particular processes of contestation - regardless of how conflictive they are.

This radical stance on power illuminates the importance of analysing how this idea is present in NGDOs perspectives: 1 ) when defining which rights are considered in their interventions; 2) when analysing the causes of rights violation; 3) when defining strategies to challenge the denial of rights together with their partners.

The notion of participation is not alien to the former issues. As previously said, RBAs had been considered a chance to attaching a value to participation in itself - and not just as a means-, and to focusing NGDO actions on mobilization and advocacy (Gready, 2009). However, a radical perspective on participation would also put emphasis not just in advocacy per se and in the democratisation of policy making or the public debate, but also in the democratisation of the advocacy and social mobilization processes and of the social organizations themselves. Consequently, from a radical 
perspective, NGDOs would not just uncritically embrace any form of advocacy; they would also look for processes which arise from autonomous, democratic grassroots organizations (Kelley, 2002), as long as they can bring to the fore legitimate and representative 'bottom-up' demands. Likewise, internal democracy in development organizations would also be an essential question to achieve coherence and gain legitimacy (Mayo, 2005). As a consequence, NGDOs would regard themselves as participatory spaces in which to build democracy (Blas and Ibarra, 2006; Gaventa, 2006b).

Therefore, it is relevant to explore how NGDOs consider democratic participation: 1) when supporting advocacy and mobilisation processes and the articulation of citizen demands; 2) in their organisational proceedings.

Lastly, and coherently with the ideas on power and participation exposed, a radical perspective would put emphasis on downwards accountability in the relationships between NGDOs and their local partners. From this perspective, NGDOs would recognise themselves as duty-bearers in relation to their partners (Jordan, 2007), and be responsive to their changing demands. That would necessarily lead to prioritising local demands, permanent dialogue and adaptation in context which are always complex. Lastly, it would be particular relevance to address how NGDOs frame accountability to their local partners in the presence of conflicting accountabilities to other stakeholders - and singularly to funders, in order to explore the implications of the adoption of RBAs by NGDOs (Gready, 2009).

\section{Methodology}

We selected a sample of 11 NGDOs according to a common criterion. All of them had launched the adoption of a RBA under the assumption that it would foster the political dimension of their work.

Interviews were held with 14 key staff members with at least four years of experience in key management positions in their NGDOs. Consequently, they knew in depth how the adoption of RBA had unfolded in their organizations. One member of the staff was interviewed in each organization, or two only when necessary. The interviews took place between November 2011 and May 2012. 
The organizations selected for the sample varied in size. Three of them were small (15 employees or fewer), five medium-sized (between 16 and 50 employees) and three large (more than 50 employees). This sample tried to consider the big differences in size in the Spanish landscape of NGDOs.

The organizations were also diverse in terms of the initial motivations they declared for adopting a RBAs. Two organisations (large and medium-size) considered RBAs as intrinsic to their nature; moreover, they affirm to have patronized this approach long before RBAs were mainstreamed into the development aid sector in Spain. A number of small, medium and large-sized organisations claimed that they gradually introduced the approach once they realised they needed to overcome 'assistentialist' thinking. A few medium-sized organisations recognised that it was precisely because of the emergence of RBAs in the aid sector and the requirements attached to public funds that they had realized the need to change their approaches. Some small and mediumsized organisations, finally, stated that they did not make any explicit decision to introduce a RBA, but that the latter had happened as a result of its own internal dynamics. This diversity tried to capture differences in the motivations in the Spanish NGDOs to adopt a RBA.

We asked interviewees about how they implement a RBA in their daily work, as well as about the organisational implications of the adoption of a RBA in: 1) relationships with partners; 2) strategic planning and areas of action of the organisation; 3) project management tools and procedures; and 4) internal organisation. The responses from our informants were triangulated with additional documents elaborated by the NGDOs (statutes, strategic plans, organisational policies and protocols, amongst others).

We adopted a qualitative strategy aimed at capturing meanings and interpretations (Corbetta, 2003). This was so because we wanted to analyse the discourses of our informants in order to understand their experiences and views about the implications of adopting RBAs. Thus, we expected to reveal not only the key issues at stake but also the underlying frameworks which legitimate, justify and give sense to the adoption of the approach.

Lastly, we processed the information by means of a qualitative content analysis based on the transcription of interviews and relevant documents from NGDOs. Inspired by Gibbs (2008), we categorized significant statements and pieces of text in charts and contrasted the codes, typologies and attributes of NGDOs. We initially drew on our 
predefined categories derived from our analytical framework, yet also refined them during the analysis and included additional dimensions and issues of interest.

\section{Exploring the adoption on RBAs in Spanish NGDOs: to what extent are they contributing to their (re)politicisation?}

\section{1. $\quad$ Framing power in relation with rights}

\subsubsection{Framing which rights are denied}

Organizations frame rights in intimate connection with how they frame power relationships. Additionally, different organizational arrangements seem to give shape to divergent framings. Our analysis reveals three categories.

The first category includes bigger organizations which embraced RBAs since their origins and which focus exclusively on legally recognised rights. Allegedly, they do so because this provides a clear mandate, legitimacy and clarity vis-à-vis third actors, and makes their claims stronger. Bigger organizations also consider that legal definitions offer uniformity and clarity, something they appreciate internally, given their size. However, some interviewees suggest that the latter may also be reinforcing inequalities of power amongst the different actors, as rights recognised by international and national laws are often defined by powerful actors, and may not be relevant for some partners. Interestingly, such critical opinions on the definitions of rights are presented as merely personal, since issues as such are not debated within the organizations.

By contrast, most NGDOs embrace a discourse which is less restrictive in this sense. This position is specific of organizations which affirm to have undergone a process of organizational change in order to adopt RBAs. On one side, these organizations articulate their own specific definitions of a handful of legally recognised rights (such as the 'right to education'). On the other, they uphold rights that are not legally recognised, yet represent combinations or reinterpretations of other rights (such as the 'right to be heard'). Organizations consider that, with these definitions, they try to have a more open and flexible perspective of rights which can avoid juridification, conserving at the same time common and clear definitions within the organizations. However, a dilemma in terms of power emerges in relation to the fact that such 
'flexible' conceptualisations are produced mainly in the headquarters of the NGDOs. Interviewees state that staff on the field, and also their counterparts, were able to take part in the discussions on the definitions on rights that these organizations consider, but also that the key discussions and decisions were essentially taken in the central headquarters, and that the definitions reflect the perspectives of experts in programming. In this sense, they work with definitions on rights which are no necessarily shared or co-constructed with their partners.

Finally, a group of small and medium organisations assert that their definition of rights 'permeated through' continual co-operation with their partners, even if they do not minimise the strategic and legitimising usefulness of legal rights, though. These organisations tend to champion visions on rights which consider political economy questions. This is, for example, the case of 'food sovereignty', an idea framing the action of several peasant movements three of the organizations interviewed work with, and which explicitly points to 'the right of peoples to decide every aspect of their food production and consumption processes' (05). It is also the case of the idea of 'right to territory', defended by some indigenous organizations which work some of the NGDOs analysed, an idea which points to the management control of natural goods by local communities. According to some interviewees, incorporating these frames has contributed to deepen the politicisation of their organisations, in terms of more of affinity and common political positions with their local partners. It seems that these organizations, being small and more flexible, and essentially driven by activist volunteers, are in a better position to co-create or assimilate the discourses coming from their partners. Additionally, these organizations do not toned to strike compromises within bigger structures, as was the case of the rest of organizations considered in this section.

\subsubsection{Framing the diagnostic: The causes of rights denial}

All the organisations in our sample stated that incorporating a RBA involves a definite move away from 'paternalist' approaches -which a few of them affirmed to have in the past- in favour of addressing the causes underlying underdevelopment. .

However, when it comes to define the concrete causes of rights violations, most statements tend to avoid issues of political economy. Most organizations express the causes of rights denial in terms of what is missing: either 'lack of public policies', 'lack of adequate legislation and legal systems', or 'lack of a strong civil society'. They also 
tend to describe problems in manageable technical terms, based either in the lack of capacities of the State, which is unable to be accountable to its citizens, or in the lack of capacities of civil society- unable to make the state accountable. This perspective seems to ignore conflict and highlight instead the lack of cooperation, consensusbuilding and dialogue between State, civil society and the private sector as the key factor underlying rights denial.

The implications of the former for some interviewees seem to be problematic. They assume that the consequence is that NGDOs must collaborate with every possible stakeholder and facilitate a deeper collaboration among them. For some interviewees, this perspective is not very critical: it fails to consider the huge power imbalances among stakeholders, and particularly the big and increasing power of some actors, such as international companies. The same interviewees, nevertheless, proclaim that it is important to be pragmatic, and assume that 'there are certain boundaries which it is not desirable to trespass' - e.g. criticising transnational companies or donors. Thus, we can reasonably assume that these organisations frame rights in ways that avoid issues of structural power as a strategy to retain credibility, financial support and the capacity to interact with authorities, big funders and other powerful actors. For example, an interviewee states:

We've never had problems with our campaigns being aggressive... well, they've never been aggressive. Because I think that the rules of the game have always been understood (...) $(08)^{1}$

In contrast, a few organisations go beyond and hold a more radical perspective. Thus, they link causes of rights violations to specific issues of political economy beyond mainstream analyses. They frequently point at the power of transnational corporations in the control of commodities and of the chains of production of goods and services at the global level as structural causes of rights violation at the local one. Specifically, three organizations mention the power over food systems by a few companies at the level of agricultural inputs - i.e. seeds-, factors of production - i.e. land and water -, and channels of distribution. They understand these processes as linked with a certain model of development, labelled as 'neoliberal', 'productivist' or 'western', which is based on the concentration of economic power, the commodification of all aspects of life, and the imposition of an ideology of consumption and modernisation. The latter speaks of a more conflictive perspective of the relationships among social organizations, private companies and the State. A consequence is that NGDOs should 
position more overtly, align with particular organizations and, eventually, explicitly confront other stakeholders. Yet pragmatic positions also arise amongst interviewees from organizations holding these positions. Thus, they see a need to moderate themselves 'in the language of the projects to be financed'. For a couple of interviewees, however, positions that explicitly accuse particular States of defending the interests of transnational companies may have affected them negatively in terms of the financial support from certain public donors.

\subsubsection{Framing the prognostic: Defining strategies to build rights}

All NGDOs in the sample seem to frame similarly the overall strategy to challenge rights denial: that is, on the one hand, working with institutions in order to make them fulfil their duties -e.g., improving the capacity of the legal systems, the capacities to implement and assess programs and projects for the most marginalized, the capacities to listen to citizen demands through different channels, etc.; on the other hand, working with citizens to promote social organization, capacity for lobbying, etc. An underlying trait in most of the discourses is that power is not considered as relational, but as an asset that stakeholders have, which can be increased through capacity building -'empowering'.

Again, the handful of organizations that diagnoses rights denial in terms of political economy also mention the control of resources as a strategy and a goal. Coherently, their strategies are twofold: on the one hand, they affirm to lobby and denounce the state towards inducing it to challenge the powerful actors which control processes of production; on the other hand, they support social organizations in their initiatives oriented to the control of resources - e.g. the actions of small farmers for the control of seeds, land or food distribution channels, as lobbying for land reform, the recovering of local knowledge and local seed varieties, the creation of alternative local distribution channels, etc.

Regardless of whether they consider political economy issues or not, every organization underscores the relevance of rethinking their relationships with Southern partners. All they speak of the importance of building 'trust', 'horizontal', 'fair' and long lasting relationships which are devoid of unequal power relationships. Most of them also make clear that to be coherent with a RBA, their relationships started to be 'more political'. Some of them state that strictly 'technical' relations premised solely on project management and resource transfer are gone since long ago. 
However, when describing these new relations the meaning of 'political' differs. In most of the cases, 'political relations' means working together following the 'political' strategies that the NGDO has defined for a country, region or sector. 'Political strategies' in this sense is defined in very vague terms, meaning producing changes in policy-making process - e.g. 'improving the capacity of policy-makers for pro-poor policy formulations' (010). From our perspective, and in the terms employed by Mosse (2005), the political would here contribute to expand 'social engineering' and managerial logics to new realms -policy-making.

Other organisations suggest a less technocratic notion of 'political' relationships could. They cite, for example, agreeing on alternative visions of development -beyond 'productivism' or 'neo-liberalism', for example. For some interviewees, political affinity as the shared analysis of questions of political economy constitutes the basis of their relationship. They strategies depart from building 'mutual political support' (O5) and trust - which, in turn may later imply common actions to change policies, but not exclusively so. The following comment illustrates the previous ideas:

The key point is... that they have to have a political and class vision... also that the organisation is democratic...and that the other organisation has a solid political outlook which is close to ours, with regard to food sovereignty. (...) Considering food sovereignty as that they [small farmers] have to be in the centre of agricultural and food systems and policies (...) We don't think that having a lot more money is much better (...) They don't see us as a source of funding, but rather as a political ally. (011)

Our analysis of how NGDOs frame the connections among power, rights, diagnostics, strategies and relations reveals different trends and dilemmas. However, we acknowledge this does not entirely capture the reality of the complex relationships of NGDOs with partners, and how practices may have changed with the adoption of a rights talk. This will need further field research and a different methodological strategy. 


\subsection{Framing participation}

\subsubsection{Participation and demanding rights}

An overall consensus seems to exist on the fact that demanding right implies for NGDOs to play a more active role channelling and mobilising demands regarding the recognition of rights, building more participatory systems and more democratic public arenas. However, differences in the perspectives emerge regarding how NGDOs consider the process of creation and the contents of the demands they support.

Most organizations show a key tension regarding participation in the process of claiming rights: on the one hand, they consider that from a RBA they have to support "bottom-up" processes of demanding rights; on the other, some interviewees recognize that, given that their NGDOs defend rights and have 'rights-inspired' values, missions and visions, they have legitimacy to act on their own in the demanding of rights. For example, persons from two of the organizations refer to big campaigns -for the defence of the right to education and of the right to food- they are promoting with another big NGOs, but without the participation of any civil society organization: 'We do not try no represent others. We have our values, and that is our source of legitimacy' (O4). Paradoxically, as the defence of rights cannot be questioned, rightstalk may provide legitimacy to non-participatory processes in the demand of rights.

Three organizations mention that they are trying to overcome this dilemma. Firstly, they make explicit that they are not legitimized to speak in the name of anyone, nor in the name of abstract values. Secondly, a key issue for them is the political economy of the production of demands. As a result, the legitimacy of their actions needs to proceed from demands that emerge from 'bottom-up' democratic processes at the grassroots level:

We speak, but the idea is to give peasants a voice - we don't want to speak on behalf of anyone. We support peasant-led processes. We do not speak in the name of values (...) Our idea and our great legitimacy is our alliance with peasant movements. (011)

However, the notions of 'grassroots' or 'bottom-up 'process' are vaguely defined. On the other hand, these organizations assume that the only way to certify the democratic of grassroots processes is by means of building trust and confidence with this kind of partners. 


\subsubsection{Framing participation within NGDOs themselves}

An interesting result of our analysis is that the ideas of internal democracy and participation within the organizations themselves are largely absent in the statements and texts that NGDOs produce. In fact, and despite their insistence on participation both as a fundamental right and as an instrument for rights fulfilment, most interviewees did not consider that NGDOs have necessarily to be democratic themselves. In this point, our analysis reveals three different positions:

In first term, those organisations exclusively working with formally recognised rights do not seem to consider hierarchies as intrinsically problematic. For them, hierarchic and non-participatory organizational models may facilitate a more efficient work; additionally, since rights are clear-cut and precisely-defined, lots of discussions within the organizations are out of place:

'We try to consider everyone's opinion, even if there is a hierarchy, that's true... But our mandate is so clear, and rights are so clear that there is not that much to discuss about. If there is a rights violation, we plan and look for the resources to improve the situation. There is little more. That is our raison d'etre' (03).

We therefore conclude that it seems, again, that rights-based discourses may be setting a limit to participation, as well as a certain over-simplification of analyses.

In a second term, other organisations acknowledge that some level of 'decentralisation' in decision-making is desirable, since it contributes to 'better management'. At the same time, they explicitly recognise that a RBA 'does not apply' (09) within the NGDO, since participation in the organization is not considered as a right for people engaged in it, but a question of efficiency, motivation and good management.

In third term, another group of organisations define themselves as 'horizontal', and point to some consequences: decision-making, information management, and planning processes must be democratic. Horizontality, nevertheless, is considered as integral to the political identity of the organisation, and independent of the adoption of a RBA. For one interviewee, such 'horizontality' refers to the relationships between paid staff, whereas for the other ones it also included volunteers. 
In fact, volunteers and their role in the NGDOs feature high amongst the dilemmas on participation. In most cases, we find that experts are central in the discourses, whereas the participation of volunteers is conceived in terms of providing support to them when implementing projects. For these interviewees, volunteers are 'not ready' to adopt more 'political' roles, maybe with the sole exception of the members of the organisation's Board. Still, at least three organizations acknowledge tensions between the centrality of experts and the horizon of participation and citizenship building they yearn for. That way, the adoption of RBA has triggered in some organizations a deep reflection about the tension between efficiency and democratic participation including volunteers- in decision making processes. In contrast, two organisations seem to hold more radical visions: Participation of volunteers is crucial and of priority importance for them, as it fosters political education and construct citizenship.

Finally, 'professionalisation' reveals itself as a relevant topic in relation to participation: Whilst several interviewees consider this process to be positive, natural or necessary, others revealed that their organisations have tried to move in the opposite direction, towards a more activist and volunteer-based organisation. This contrast reinforces the idea that some organizations prioritise efficiency whilst others seek activist participation.

\subsection{Framing downwards accountability}

Our sample of organizations shares some common ideas about accountability. Broadly speaking, all of them emphasized that the adoption of a RBA necessarily implies bigger efforts in this sense. In particularly, it implies to be accountable not only to the public or donors, but also to other supporters and, specially, to local partners in the South that is, downwards accountability.

All organizations saw demands of accountability coming from public donors, particularly financial accountability, as largely detrimental for downwards accountability. Such accountability almost invariably implies big bureaucracies and a heavy burden in their daily work. Consequently, political action and downwards accountability can hardly be fulfilled.

Yet apart from these common perceptions, organizations diverge when identifying related problems regarding accountability. On the one hand, a majority of 
interviewees underscore technical problems, such as 'measuring' the results, impact or efficiency of 'rights-based' actions - e.g. advocacy or social mobilisation. They are difficult to convey to donors, the public and the local partners. They affirm that this is a new challenge that they did not endured before, since under more 'paternalistic' approaches results were easier to estimate - e.g. the 'number of schools built' (O4). Thus, new mechanisms and indicators for quantifying and assessing rights-based actions are needed, but they are still in their infancy.

In contrast, those smaller organizations which consider themselves more permeated by social movements, reflected in less managerial terms about conflicting accountabilities. For them, the key issue is that demands of accountability coming from donors and from their partners are incompatible. On one side, donors continue to be concerned with measurable impacts and entail a simplified vision of highly complex political processes. On the other, their local partners are not really interested in measurement, and they continuously change their demands, as they are immersed in complex and changing contexts and processes. To face such tensions, organisations affirm to use a 'double language': they accept the demands coming from local organisations whilst at the same time paying lip service to the bureaucratic language and procedural requirements of donors. In the process, eventually, some information is kept away or distorted from donors. As said by an interviewee:

Since the nineties, we've worked with the notion of two projects - we have become experts in [using] a double language. And that is getting ever more difficult. (...) People who work for donors are very qualified... But it is more clear every time the contradiction between the needs of the project and the indigenous communities and the bureaucratic and procedural requirements. (09)

By contrast, at least two interviewees affirm that requests from donors to 'use' a RBA in project planning might have facilitated their work with social movements. This is so because in spite of some rigidity, requirements as such seem to legitimise the language of rights they have already been using before RBAs were mainstreamed in the aid sector and donor's discourses. 


\section{Conclusions}

Our analysis reveals a diverse landscape of modalities to incorporate RBAs in Spanish NGDOs. However, two archetypical trends can be identified regarding their implications for (re)politicisation of NGDOs:

The first trend seems to be consolidating a rationale in the organisations rooted in a managerial and depoliticised perspective. For some NGDOs and in some aspects, RBAs are a new tool to improve their effectiveness and the impact of their actions. They are useful to move away from assistentialist approaches and address the root causes of rights denial. However, they tend to define problems in technical and manageable terms in agreement with dominant discourses, without political economy considerations. These NGDOs seem to exclusively consider, face-to-face local organisations, the frames and strategies which derive from their own understanding of rights, with little influence from local perspectives. In terms of participation, 'experts' continue to play a central role, while internal organisation is preferably understood in terms of efficiency, giving volunteers the role of mere implementers. They affirm to advance claims from civil society, but they avoid radical political positions and confronting authorities. They essentially emphasise technical accountability, as well as measuring and proving evidence of the effectiveness of their new approach.

A second pattern seems to incorporate more radical implications of adopting a rightstalk. Some of the NGDOs under analysis might be embracing, through the adoption of a RBA, more critical and political analyses of the causes of rights violations, as well as new formulations of rights and political strategies, emerging from their shared work with their partners. Rather than efficiency and management, some organisations confer value to coherence in the different aspects of the organisations. Democratic participation in the construction of demands is a key issue, and the organisation itself is considered as a space for the construction of democracy and citizenship. Finally, they view accountability primarily in terms of responding to the changing demands of their allied organisations, and try to navigate the tensions which arise out of the demands of donors.

However, we cannot set clear cut-boundaries between those two patterns, and it is not possible to clearly place the NGDOs in our sample in one of them. Both trends seem to exist in every organisation to some extent. We nevertheless dare to posit that some organisations, particularly those of larger size, stand closer to the first pattern. 
Amongst them, it seems that managerial and uncritical visions have been present since long; that rigid structures leave little room to the influence of partner organisations and local perspectives; and that pressures for getting financial resources are bigger. Another group of organisations, particularly those of smaller size, seem to be closer to the second trend. They seem to be more flexible and tightly connected to partners rooted in their local contexts and holding more political positions. These NGDOs made critical statements and saw themselves as political before they embraced a RBA discourse.

It is therefore difficult to conclude whether RBAs are facilitating changes in NGDOs towards politicisation. Although adopting RBAs may not effect major changes per se, it can still be triggering some reflections, legitimating some practices, and strengthening existing processes of politicisation in some NGDOs. Yet the potential of RBAs seems to be limited and can be captured by managerial logics. This may be due both to external pressures that NGDO face and to built-in organisational inertia. Organisations are pressed by the demands of Spanish donors, such as project-centred interventions, results-based approaches or logical frameworks. In addition, it also seems that the potential of RBAs to transform practice is also strongly curtailed by the organisational culture of the NGDO: Vertical structures, rigid 'top-down' managerial planning and management procedures, the aversion to conflict with public institutions and the reluctance to assume some critical or radical discourses feature amongst organisational features of that kind. In order to prevent RBAs to be captured by managerial logics, it seems that significant changes may be necessary both in aid policies and in organisational cultures and structures.

Summing up, the analysis can enable us to affirm that the adoption of RBAs by Spanish NGOs is a process full of diversity, tensions, contrasts and contradictions, both across and inside different organisations. In some aspects and NGDOs, RBAs could be consolidating managerial perspectives; yet, in other cases, the opposite could also be true. That probably has to do with the diversity of backgrounds, profiles, organisational cultures and previous political stances of the NGDOs, as well as with their different position in front of the managerial pressures which arise from aid policies. It is also to say that, given that this diversity and pressures also exist in the NGDO sector in other Northern countries, the results of research in Spain may be relevant for approaching other contexts. 
We believe that the framework we proposed has facilitated the identification and analysis of key issues regarding different aspects of the organisations. In that sense, it has proved useful for a first approach to our guiding question, despite the limitations derived from the large amount of issues under scrutiny, which made difficult to deep into each one. Future research could benefit from a focus on more specific questions, new theoretical elements, and an increased number of organisations under study.

\section{Endnotes}

\footnotetext{
1 "O[number]" refers to the number assigned to the interviewee's organisation for the purposes of this study.
}

\section{References}

Aberese, M, Akua N. and Crawford, G. (2013), 'NGOs, Rights-Based Approaches and the potential for progressive development in local contexts: constraints and challenges in Northern Ghana', Journal of Human Rights Practice, 5 (1), 46-74.

ActionAid (2010), Action on Rights. Human Rights Based Approach Resource Book. Johannesburg, ActionAid.

Blas, A., and Ibarra, P. (2006), 'La Participación: Estado de la Cuestión' (Cuaderno de Trabajo 39), Bilbao, Instituto Hegoa.

Belda, S., Boni, A., Peris, J., and Terol, L. (2012), 'Rethinking capacity development for critical development practice. Inquiry into a postgraduate programme', Journal of International Development, 24 (5), 531-665.

Blichner, L.C. and Molander, A. (2008), 'Mapping juridification', European Law Journal, 14(1), 36-54.

Choudry, A., and Shragge, E. (2011), 'Disciplining dissent: NGOs and community organisations', Globalizations, 8 (4), 503-517.

Corbetta, P. (2003), Metodología y técnicas de investigación social, Madrid, McGrawHill. 
Cornwall, A. (2007), 'Buzzwords and fuzzwords: deconstructing development discourse', Development in practice, 17(4-5), 471-484.

Cornwall, A., and Molyneux, M. (2006), 'The politics of rights - dilemmas for feminist practices: an introduction', Third World Quarterly, 27 (7), 1175-1191.

Dar, S., and Cooke, B. (2008). 'Introduction: the new development management', in S. Dar and B. Cooke (eds.), The New Development Management: Critiquing the Dual Modernization, London, Zed Books, 1-17.

Escobar, A. (2008), 'Afterword', in S. Dar and B. Cooke (eds.), The New Development Management: Critiquing the Dual Modernization, London, Zed Books, 193-203.

Evans, T. (2005), 'International human rights law as power/knowledge', Human Rights Quarterly, 27 (3), 1046-1068.

Eyben, R. (2005), 'Donors' learning difficulties: results, relationships and responsibilities', IDS Bulletin, 36 (3), 98-107.

Eyben, R. (2008), 'Power, Mutual Accountability and Responsibility in the Practice of International Aid: A Relational Approach' (IDS Working Paper 305), Brighton, Institute of Development Studies.

Ferguson, J. (1990), The Anti-Politics Machine: Development, Depoliticisation and Bureaucratic Power in Lesotho, Indianapolis, University of Minnesota Press.

Fernández, G., Piris, S., and Ramiro, P. (2013), Cooperación Internacional y Movimientos Sociales Emancipadores: Bases para un Encuentro Necesario, Bilbao, Instituto Hegoa.

Fowler, A. (1998), 'Authentic NGDO partnerships in the new policy agenda for international aid: dead end or light ahead?', Development and Change, 29(1), 137-159.

Gauri, V., and Gloppen, S. (2012), 'Human Rights Approaches to Development. Concepts, Evidence and Policy' (Policy Research Working Paper 5938), Washington, World Bank.

Gaventa, J. (2006a), 'Finding the spaces for change: a power analysis', IDS Bulletin 37 (6), 23-33. 
Gaventa, J. (2006b), 'Triumph, Deficit or Contestation? Deepening the 'Deepening Democracy' Debate' (IDS Working Paper 264). Brighton, Institute of Development Studies.

Gibbs, G.R. (2008), Analysing Qualitative Data, London, SAGE Publications Ltd.

Gready, P. (2008), 'Rights-based approaches to development: what is the value added?', Development in Practice, 18 (6), 735-747.

Gready, P. (2009), 'Reasons to be cautious about evidence and evaluation: rights-based approaches to development and the emerging culture of evaluation', Journal of Human Rights Practice, 1 (3), 380-401.

Gready, P., and Ensor, J. (2005), 'Introduction', in P. Gready and J. Ensor (eds.), Reinventing Development? Translating Rights-based Approach from Theory Into Practice, London, Zed Books, 1-44.

Grey, C. (1996), 'Towards a critique of managerialism: the contribution of Simone Weil', Journal of Management Studies, 33 (5), 591-611.

Gulrajani, N. (2010), 'New vistas for development management: examining radicalreformist possibilities and potential', Public Administration and Development, 30 (2), 136-148.

Harvey, D. (2000), Spaces of Hope, Berkeley, University of California Press.

Hickey, S., and Mitlin, D. (eds.) (2009), Rights-Based Approaches to Development. Exploring the Potential and Pitfalls, Sterling, Kumarian Press.

Hickey, S., and Mohan, G. (2005), 'Relocating participation within a radical politics of development', Development and Change, 36 (2), 237-262.

Jordan, L. (2007), 'A rights-based approach to accountability', in A. Ebrahim and E. Weisband (eds.), Global Accountabilities. Participation, Pluralism and Public Ethics, Sterling, Kumarian Press, 151-167.

Kelley, R.D.G. (2002), Freedom Dreams: the Black Radical Imagination, Boston, Beacon Press.

Kindornay, S., Ron, J., and Carpenter, C. (2012), 'Rights-Based Approaches to development: implications for NGOs', Human Rights Quarterly, 34 (2), 472-506. 
Li, T. (1999), Compromising power: development, culture, and rule in Indonesia. Cultural Anthropology, 295-322.

Li, T. (2007), The will to improve: Governmentality, Development and the Practice of Politics, Durham and London, Duke University Press.

Maier, F., and Meyer, M. (2011), 'Managerialism and beyond: discourses of civil society organisation and their governance implications', Voluntas: International Journal of Voluntary and Nonprofit Organisations, 22 (4), 731-756.

Mayo, M. (2005), Global Citizens. Social Movements and the Challenge of Globalization, London, Zed Books.

Martínez-Osés, P. (2011), 'Redefinición del papel de las ONG: hacia una mirada más política", paper for the Jornadas Eficacia del Desarrollo y ONGDs: renovando nuestro papel, Madrid, 17 and 18 May 2011, available http://www.2015ymas.org/IMG/pdf/Pablo_Martinez_Oses.pdf [accessed 3 july 2013].

McCourt, W. (2008), 'Public management in developing countries', Public Management Review 10 (4), 467-479.

McGee, R. (2010), 'Procesos de Desarrollo, participación, gobernanza, derechos y poder' (Cuadernos de Investigación en Procesos de Desarrollo 1), Valencia, Grupo de Estudios en Desarrollo, Cooperación y Ética.

Meyer, M., Buber, R., and Aghamanoukjan, A. (2012), 'In search of legitimacy: managerialism and legitimation in civil society organisations', Voluntas: International Journal of Voluntary and Nonprofit Organisations, 24 (1), 167-193.

Mosse, D. (2005), Cultivating Development: An Ethnography of Aid Policy and Practice, London, Pluto Press.

Mowles, C. (2010), Post-foundational development management - power, politics and complexity, Public Administration and Development, 30, 149-158.

Mowles, C., Stacey, R., and Griffin, D. (2008), 'What contribution can insights from the complexity sciences make to the theory and practice of development management?', Journal of International Development, 20 (6), 804-820. 
Nyamu-Musembi, C., and Cornwall, A. (2004). 'What is the 'rights-based approach' all about? Perspectives from international development agencies' (IDS Working Paper 234), Brighton, Institute of Development Studies.

Parker, M. (2002), Against Management: Organisation in the Age of Managerialism, Cambridge, Polity.

Quarles van Ufford, P., and Giri, A. (2003), A Moral Critique of Development: In Search of Global Responsibilities, London, Routledge.

Revilla Blanco, M. (ed.) (2002), Las ONG y la Política, Madrid, Akal.

Offenheiser R., and Holcombe, S.H. (2003), 'Challenges and opportunities in implementing a rights-based approach to development: an Oxfam America perspective', Nonprofit and Voluntary Sector Quarterly, 32 (2), 268-301.

Plipat, S. (2005), 'Developmentizing human rights: how development NGOs interpret and implement a human rights-based approach to development policy' (unpublished doctoral dissertation), Pittsburgh, University of Pittsburgh.

Revilla, M.T. (2002), Las ONG y la política, Madrid, Istmo.

Schattschenider, E.E. (1960), The Semisovereign People: A Realist's View of Democracy in America, New York, Holt, Rinehart and Winston.

Schmitz, H.P. (2012), 'A human rights-based approach in practice: evaluating NGO development efforts', Polity, 44 (4), 523-541.

Srinivas, N. (2009), 'Against NGOs? A critical perspective on nongovernmental action', Nonprofit and Voluntary Sector Quarterly, 38 (4), 614-626.

Uvin, P. (2007), 'From the right to development to the rights-based approach: how 'human rights' entered development', Development in Practice, 17 (4-5), 597-606.

VeneKlassen, L., Miller, V., Clark, C., and Reilly, M. (2004), Rights-Based Approaches and Beyond. Linking Rights and Participation: Challenges of Current Thinking and Action, Washington, Just Associates.

Wallace, T., Bornstein, L., and Chapman, J. (2007), The Aid Chain: Coercion and Commitment in Development NGOs, Kampala, Practical Action Publishing. 